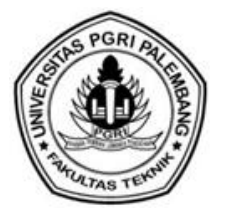

\title{
EFISIENSI MOTOR INDUKSI JENIS SHADED POLE SEBAGAI PENGGERAK BLOWER
}

\author{
M. Saleh Al Amin ${ }^{1}$, Emidiana $^{2}$ \\ Program Studi Teknik Elektro Universitas PGRI Palembang \\ email :' salehamin@ univpgri-palembang.ac.id, 2emidiana@ univpgri-palembang.ac.id,
}

\begin{abstract}
Abstrak--Motor induksi jenis kutub terbelah (shaded pole) paling banyak digunakan untuk penggunaan seharihari, yaitu untuk kebutuhan dengan daya rendah, seperti : penggerak kipas angin atau blower. Tetapi dalam penggunannya, motor tersebut cepat mengalami penurunan kecepatan dan suaranya semakin keras. Hal ini disebabkan karena tingginya nilai rugi-rugi pada motor tersebut, yang berakibat rendahnya niali efisiennya, yaitu 59,1\%. Rugi-rugi yang tinggi menyebabkan motor menjadi panas, sehingga kecepatannya menurun dan suaranya semakin bising. Pada motor induksi jenis shaded pole, inti besinya sangat dominant, dapat mencapai $60 \%$ dari total material motor. Hal ini akan membuat jalur lintasan medan magnetnya panjang, yang dapat mengakibatkan rendahnya efisiensi motor. Untuk mengatasi efisiensi yang rendah tersebut, maka sebaiknya dimensi kawat kumparan motor diperbesar untuk menurunkan impedansi motor.

Kata kunci : motor induksi, efisiensi, shaded pole

Abstract--Shaded pole induction motors are most widely used for everyday use, for low-power equipment, such as: fan or blower drive. But in use, the motor quickly decreases its speed and the sound gets louder. This is due to the high value of the losses on the motor, which results in a low value of efficiency, 59.1\%. High losses cause the motor to heat up, so that the speed decreases and the sound becomes even more noisy. In the shaded pole induction motor, the iron core is very dominant, it can reach $60 \%$ of the total motor material. This will make the magnetic field path long, which can result in lower motor efficiency. To resolve this low efficiency, it is better if the motor coil wire dimensions are enlarged to reduce the motor impedance.

Key words: induction motor, efficiency, shaded pole
\end{abstract}

\section{PENDAHULUAN}

Dalam pengoperasiannya motor penggerak kipas angin atau blower sering mengalami gangguan, seperti penurunan putaran saat beberapa lama beroperasi, sehingga akan mengurangi kinerja dari kipas angin atau blower. Penurunan putaran tersebut disertai dengan suara yang semakin kasar, karena terjadinya vibrasi yang naik pada motor, dan temperatur motor semakin naik. Dengan demikian perlu untuk dilakukan pengamatan dan perhitungan untuk mengetahui penyebab penurunan putaran tersebut.

Motor penggerak kipas angin atau blower tersebut merupakan motor induksi jenis shaded pole atau kumparan terpisah, dimana prinsip kerjanya merupakan kombinasi antara motor induksi dan transformator.

Pada penelitian ini akan dihitung effisiensi motor induksi jenis shaded pole dengan daya150 Watt.

\section{TINJAUAN PUSTAKA}

Dalam kehidupan sehari-hari, motor induksi banyak digunakan karena mudah dalam pengoperasian dan murah harganya. Motor induksi biasanya digunakan sebagai penggerak alat dengan daya rendah dan kecepatan yang relatif konstan. Hal ini disebabkan, konstruksinya yang sederhana dan kecepatannya yang mendekati konstan. Penggunannya dalam kehidupan sehari-hari antara lain : sebagai penggerak kipas angin, pompa air, dll.[1] 
Mesin induksi 1 fasa secara umum konstruksinya sama dengan mesin induksi 3 fasa, yang membedakannya adalah kumparan stator nya berupa belitan satu fasa, selain itu motor induksi 1 fasa mempunyai suatu sakelar sentrifugal untuk start, karena fluks yang dihasilkan kumparan stator 1 fasa bukan medan putar, melainkan medan bolak-balik[2]

Prinsip kerja motor induksi sama dengan prinsip kerja transformator, yaitu : berdasarkan prinsip induksi elektromagnetik, oleh karena itu, motor induksi dapat dianggap sebagai trafo dengan kumparan sekunder yang berputar[3]

Motor induksi 1-fasa merupakan motor listrik arus bolak balik yang bekerja dengan prinsip : induksi medan magnet dari kumparan stator ke kumparan rotor. Motor induksi ini biasanya mempunyai 2 buah kumparan yang disebut dengan kumparan utama dan kumparan bantu.[4]

\section{Motor Kutub Bayangan (Shaded Pole)}

Motor induksi jenis Shaded Pole merupakan salah satu jenis motor induksi yang kutubnya terbentuk dari sebuah inti besi yang dipisahkan dengan membuat potongan lekukan pada inti besi tersebut, sehingga membentuk fasa yang terbelah, dan diberi kumparan yang terhubung singkat berupa cincin. Kumparan motor induksi jenis ini berupa kumparan yang sama dengan kumparan pada transformator.

Motor kutub bayangan (Shaded pole) ini menggunakan kutup magnet stator yang dibelah dan diberi cincin pada bagian kutup yang kecil yang disebut kutup bayangan, dan sisi kutup yang besar disebut kutub pokok (Un shaded pole) dengan rotor yang biasa digunakan adalah rotor sangkar tupai. Motor kutub bayangan ini biasanya diterapkan untuk kapasitas yang kecil dan sering dijumpai pada motor-motor kipas angin yang kecil[5]. Motor 1 fasa yang paling banyak digunakan adalah motor jenis shaded pole (Phase belah/split phase), yang menggunakan sumber listrik arus tukar[6]

Pengertian dasar dari shaded pole adalah kutub terbelah. Pembelahan kutub ini dimaksudkan untuk membentuk terjadinya medan putar sebagai pemicu start awal dari motor induksi. Motor shaded pole ini dilukiskan pada gambar berikut :

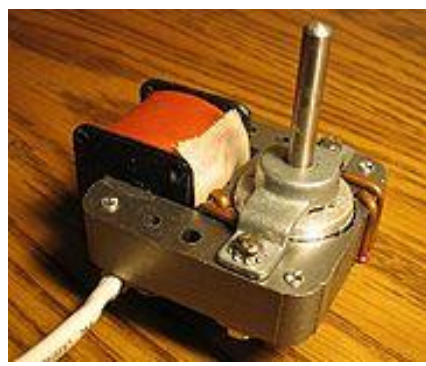

(a)

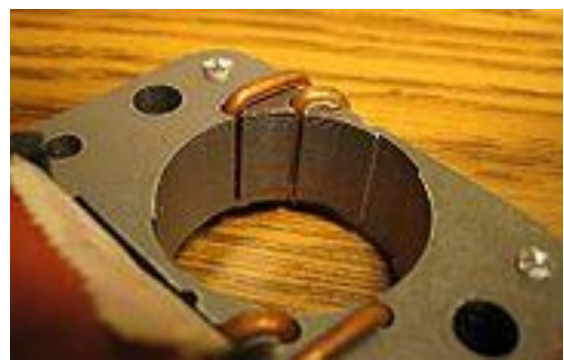

(b)

Gambar 1. Bentuk fisik Motor shaded pole. (a) Bentuk lengkap.

(b) Bentuk stator. 


\section{Prinsip kerja motor shaded pole.}

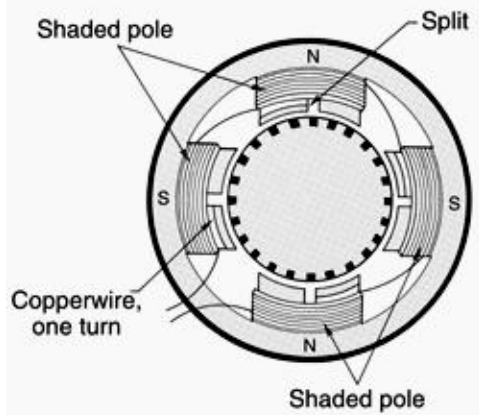

Gambar 2. Bentuk kutub dan kumparan motor shaded pole.

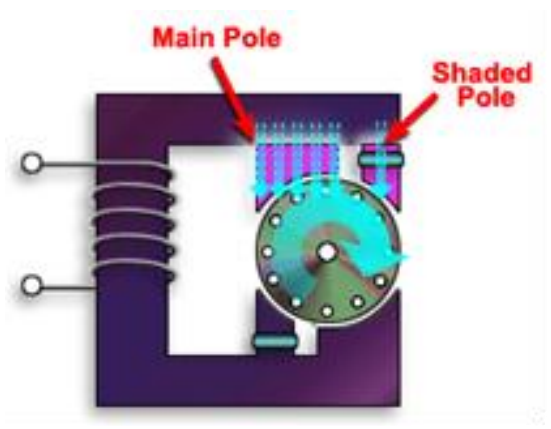

Gambar 3. Arah medan magnet dan arah putaran

Motor shaded pole bekerja berdasarkan induksi elektromagnet, dimana fluksi magnet dihasilkan pada inti stator, dari induksi kumparan pada inti stator tersebut.

1. Bila kumparan (seperti kumparan transformator) dari motor shaded pole dimasukkan ke sumber tegangan bolak-balik satu fasa, maka akan mengalir arus pada kumparan tersebut, hingga akan berlaku hukum Biot-Savart, yaitu akan menghasilkan medan magnet induksi pada inti besi.

2. Fluksi pada inti besi tersebut akan mengalir di seluruh inti dan pada kutub utama akan mengalir dari Utara ke Selatan dengan memotong inti rotor.

3. Pada kutub shaded diberi cincin konduktor yang berfungsi untuk membentuk perlambatan fluksi pada inti tersebut, seolah-olah akan terjadi beda fasa antara kutub utama dan kutub shaded, sehingga akan terbentuk medan putar.

4. Fluksi akan berputar dari kutub utama ke kutub shaded dengan sudut lancip, hingga antara Kutub Utara dan selatan akan terbentuk kutub bantu yang secara vektoris dilukiskan sebagai berikut :

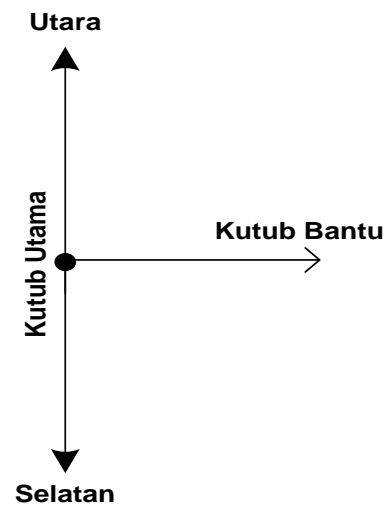

Gambar 4. Vektor kutub utama dan kutub bantu.

5. Dengan adanya kutub bantu tersebut maka akan terbentuk medan putar antara kutub utama dan kutub bantu yang arahnya dari kutub utama utara ke arah kutub bantu, lalu ke arah selatan dari kutub utama. 
6. Rotor akan menerima induksi elektromagnet dari fluksi yang mengalir, sehingga akan terjadi arus pada kumparan rotor yang akan berinteraksi dengan medan magnet dari stator, yang menghasilkan gaya Lorenz yang besarnya adalah :

$$
\mathrm{F}=\text { B.I. } \ell \text { Newton. }
$$

Gaya tesebut akan menimbulkan Torsi awal (Torka) pada rotor, besarnya adalah :

$$
\mathrm{T}=\mathrm{F} \cdot \mathrm{r} \text { Newton . meter }(\mathrm{N}-\mathrm{m})
$$

Dimana :

- F: Gaya Lorenz (Newton).

- B : Kerapatan Fluksi pada inti besi (Weber $/ \mathrm{m}^{2}$ ).

- I : Arus pada kumparan rotor (ampere).

- $\quad \ell \quad$ : Panjang lintasan fluksi (meter).

Dengan adanya torka tersebut, maka akan terjadi putaran rotor, karena torka adalah gaya putar rotor, dengan ketentuan sebagai berikut :

Rotor berputar bila $\mathrm{T}>\mathrm{Td}$.

Td : Torsi diam rotor.

\section{METODE PENELITIAN}

Langkah-langkah perhitungan :

1. Menentukan parameter motor.

a. Parameter konstan : resistansi $\mathrm{R}_{1}, \mathrm{R}_{2}$, reaktansi $\mathrm{X}_{1}, \mathrm{X}_{2}$ 'dan impedansi motor $\mathrm{Z}_{2}$

b. Parameter Variabel : arus $\mathrm{I}_{1}, \mathrm{I}_{0}$ dan tegangan $\mathrm{V}_{1}$,

2. Menentukan rugi-rugi motor.

Rugi-rugi daya dapat ditentukan setelah data-data parameter konstan berupa resistansi motor telah diketahui. Rugi-rugi daya yang terdapat pada motor induksi shaded pole sama dengan rugi-rugi daya yang terdapat pada motor induksi pada umumnya, yaitu

- Rugi-rugi tembaga.

- Rugi-rugi inti, yang ada pada bagian stator maupun rotor, terdiri dari : rugi-rugi inti histeresis dan rugi-rugi arus pusar (rugi-rugi arus eddy) [6].

- Rugi-rugi gesekan.

- Rugi-rugi angin.

Karena motor induksi shaded pole ini merupakan motor dengan daya yang kecil, yaitu sekitar 150 Watt, maka rugi-rugi inti, rugi-rugi gesekan dan rugi-rugi angin dapat diabaikan. Dengan demikian yang diperhitungkan di sini hanya rugi-rugi daya berupa rugi-rugi tembaga saja, yang besarnya adalah :

$$
\Delta \mathrm{P}=\mathrm{I}^{2} \cdot \mathrm{R} \quad \text { (watt) }
$$

Karena impedansi motor mengandung $\mathrm{R}_{1}$ dan $\mathrm{R}_{2}$ ' maka rugi inti yang terjadi pada motor merupakan gabungan antara rugi-rugi pada $\mathrm{R}_{1}$ dan rugi-rugi pada $\mathrm{R}_{2}$. Maka rugi-rugi daya pada motor shaded pole adalah :

$$
\Delta \mathrm{P}=\left(\mathrm{I}_{2}{ }^{\prime}\right)^{2} \cdot\left(\mathrm{R}_{1}+\mathrm{R}_{2}{ }^{\prime}\right) \quad(\text { watt })
$$

Dimana :

$\Delta \mathrm{P} \quad$ : Rugi-rugi daya motor (watt).

$\mathrm{I}_{2} \quad$ : Arus pengganti dari arus motor pada saat beroperasi.

$\mathrm{R}_{1} \quad$ : Resistansi kumparan motor pada saat motor diam (tidak beroperasi).

$\mathrm{R}_{2}{ }^{\prime} \quad$ : Resistansi kumparan motor pengganti pada saat beroperasi. 
3. Menentukan daya yang diserap oleh motor.

Daya yang diserap oleh motor yang sedang beroperasi dapat ditentukan dengan menggunakan persamaan berikut :

$$
\mathrm{P} \quad=\mathrm{V} . \mathrm{I} \cdot \operatorname{Cos} \phi \quad(\text { watt })
$$

Untuk sistem satu fasa, diasumsikan bahwa $\operatorname{Cos} \phi=1$ (unity), sehingga persamaan diatas akan menjadi :

$$
\mathrm{P} \quad=\mathrm{V} . \mathrm{I} \quad(\text { watt })
$$

Dalam hal ini tegangan (V) dan arus (I) diperoleh dari hasil pengukuran, sehingga dengan cara ini nilai daya $(\mathrm{P})$ yang diperoleh akan terjadi deviasi atau penyimpangan yang lebih besar dibandingkan dengan cara pengukuran langsung, karena dalam perhitungan juga akan dijumpai adanya error dalam pembulatan hasil perhitungan, disamping penyimpangan dalam pengukuran.

4. Menentukan daya yang terpakai.

Daya yang diserap oleh motor induksi shaded pole ini tidak seluruhnya akan diubah menjadi energi mekanis berupa putaran, tetapi sebagian akan diubah menjadi panas yang merupakan rugi-rugi daya. Maka daya yang diubah menjadi energi mekanis merupakan daya yang terpakai oleh motor. Dengan demikian besarnya daya yang terpakai dapat ditentukan sebagai berikut :

$$
\mathrm{P}_{\text {out }}=\mathrm{P}-\Delta \mathrm{P} \quad \text { (watt) }
$$

Dimana :

$$
\begin{array}{ll}
\mathrm{P}_{\text {out }} & : \text { Daya yang terpakai (watt). } \\
\mathrm{P} & : \text { Daya yang diserap oleh motor (watt). } \\
\Delta \mathrm{P} & : \text { Rugi-rugi daya (watt). }
\end{array}
$$

5. Menentukan efisisensi motor shaded pole $(\eta)$.

Efisiensi motor shaded pole sama seperti pada motor induksi jenis lainnya, yaitu perbandingan antara data yang terpakai terhadap daya yang diserap oleh motor pada saat beroperasi. Maka efisiensi motor shaded pole adalah :

$$
\eta=\frac{P-\Delta P}{P}
$$

Atau :

$$
\begin{aligned}
\eta & =\frac{P_{\text {out }}}{P} \\
\eta & =\frac{P_{\text {out }}}{P} \times 100 \%
\end{aligned}
$$

\section{HASIL DAN PEMBAHASAN}

1. Parameter konstan motor induksi

Dari hasil perhitungan didapat parameter motor shaded pole $150 \mathrm{Watt}$, yaitu :

$$
\begin{array}{ll}
\mathrm{R}_{1}=90 \mathrm{Ohm} . & \mathrm{X}_{1}=65,14 \mathrm{Ohm} . \\
\mathrm{R}_{2}{ }^{\prime}=38,57 \mathrm{Ohm} . & \mathrm{X}_{2}{ }^{\prime}=25,21 \mathrm{Ohm} .
\end{array}
$$

2. Rugi-rugi Daya Motor

Besarnya rugi-rugi daya motor adalah :

$$
\Delta \mathrm{P}=(0,7)^{2} .(128,57) \text { watt. }
$$




$$
\Delta \mathrm{P}=62,99 \text { watt. }
$$

3. Daya yang diserap Motor

Daya yang diserap oleh motor adalah sebagai berikut :

$$
\begin{aligned}
& \mathrm{P}=(220) .(0,7) \text { watt. } \\
& \mathrm{P}=154 \text { watt. }
\end{aligned}
$$

4. Daya yang terpakai oleh Motor

Besarnya daya yang terpakai oleh motor adalah sebagai berikut :

$$
\begin{aligned}
& \mathrm{P}_{\text {out }}=154 \text { watt }-62,99 \text { watt } \\
& \mathrm{P}_{\text {out }}=91,01 \text { watt. }
\end{aligned}
$$

5. Efisiensi motor.

Nilai efisiensi motor shaded pole dapat ditentukan dengan menggunakan persamaan sebagai berikut:

$$
\eta \quad=\frac{P_{\text {out }}}{P} \times 100 \%
$$

Dari hasil perhitungan sebelumnya telah diperoleh nilai-nilai sebagai berikut :

$$
\begin{aligned}
& \mathrm{P}_{\mathrm{m}}=91,01 \text { watt. } \\
& \mathrm{P}=154 \text { watt. }
\end{aligned}
$$

Maka nilai efisiensi dapat ditentukan sebagai berikut :

$$
\begin{aligned}
\eta & =\frac{91,01}{154} \times 100 \% \\
\eta & =59,1 \% .
\end{aligned}
$$

Dari hasil perhitungan telah diperoleh efisiensi motor shaded pole adalah sebesar $59,1 \%$. Rendahnya efisiensi motor shaded pole ini karena adanya rugi-rugi daya yng besar, yaitu sebesar 40,9 $\%$. Memang motor induksi jenis shaded pole merupakan motor induksi dimana inti besinya sangat dominant, dapat mencapai $60 \%$ dari total material motor. Hal ini akan membuat jalur lintasan medan magnetnya panjang, yang dapat mengakibatkan rendahnya efisiensi motor.

Semakin lama pengoperasian motor, maka kumparan motor akan panas yang akan mengakibatkan terjadinya penyimpangan parameter motor tersebut. Hal ini ditandai dengan menurunnya putaran motor dan motor, seperti pada tabel di bawah ini. Demikian juga dengan suara motor akan semakin kasar, yang dapat merusak bearing motor. Untuk mengatasinya adalah dengan memperbesar ukuran kawat kumparan dan memperkecil ukuran inti agar medan magnetnya akan bertambah besar, dan efisiensi motor akan makin besar pula.

\section{KESIMPULAN}

Dari hasil perhitungan dan analisis dapat disimpulkan yaitu :

1. Efisiensi yang diperoleh dari hasil perhitungan adalah sebesar 59,1\% yang dikategorikan sebagai efisiensi yang rendah.

2. Efisiensi yang rendah ini disebabkan, tingginya rugi-rugi pada motor ini, karena $60 \%$ materialnya adalah inti besi

\section{DAFTAR PUSTAKA}

[1] Emidiana, E. (2017). Pengaruh Kapasitas Kapasitor Pada Kumparan Bantu Terhadap Pemanasan Motor Induksi Satu Fasa. Jurnal Ampere, 2(2), 81-87 
[2] Prof. Ir. Abdul Kadir. (2003). Mesin Induksi. Penerbit Djambatan

[3] Drs Yon Rijono. (2002). Dasar teknik Tenaga Listrik. Penerbit Andi Yogyakarta

[4] Anthony, Z., Erhaneli, E., Ismail, F., Kurniawan, F., Hasanah, M., Putra, H., \& Purnomo, A. (2019). Sistem Kendali Arus Kumparan Motor Induksi 1 Fasa Dengan Menggunakan Arduino. Jurnal Teknik Elektro, 8(2), 76-81.

[5] Zuriman Anthony, Mesin Listrik AC

https://sisfo.itp.ac.id/bahanajar/BahanAjar/ZurimanAnthony/Mesin\%20Listrik\%20AC/Bab\%20IV. pdf

[6] Drs. Yon Rijono, "Dasar Teknik Tenaga Listrik", Penerbit Andi, Yogyalarta, 2002 